Portland State University

PDXScholar

$1-1-2011$

\title{
Social and Human Capital: Contributing Effects of Incarceration on Neighborhoods
}

Jacqueline Victoria Swofford

Portland State University

Follow this and additional works at: https://pdxscholar.library.pdx.edu/open_access_etds Let us know how access to this document benefits you.

\section{Recommended Citation}

Swofford, Jacqueline Victoria, "Social and Human Capital: Contributing Effects of Incarceration on Neighborhoods" (2011). Dissertations and Theses. Paper 261.

https://doi.org/10.15760/etd.261

This Thesis is brought to you for free and open access. It has been accepted for inclusion in Dissertations and Theses by an authorized administrator of PDXScholar. Please contact us if we can make this document more accessible: pdxscholar@pdx.edu. 


\title{
Social and Human Capital:
}

\section{Contributing Effects of Incarceration on Neighborhoods}

\section{by}

\section{Jacqueline Victoria Swofford}

A thesis submitted in partial fulfillment of the requirements for the degree of

\author{
Master of Science \\ in \\ Criminology and Criminal Justice
}

Thesis Committee: Jody Sundt, Chair Brian Renauer

Kris Henning

Portland State University 2011 


\begin{abstract}
Interest in human and social capital's contribution to the desistence of crime is increasingly popular amongst criminologists, economists and policy makers. However, little attention has been drawn to the influence human and social capital indicators contribute towards the relationship between the re-entry process and juvenile crime at the neighborhood level. The current study hypothesizes the existence of a mediating relationship between human and social capital indicators (2000) and the rates of receiving formerly incarcerated persons (1997-2002) and juvenile arrest (2006-08) in 92 Portland, Oregon neighborhoods. Portland, Oregon receives more formerly incarcerated persons from Oregon's state correctional facilities than any other city or county in Oregon. Using neighborhood rates of residents with house-hold income above $50 \mathrm{~K}$, high school graduation, and annual income type: retired or government assistance, as proxies for human capital measures and neighborhood rates of residents employed by non-profit organizations, number of churches, and self-employment as proxies for social capital measures, OLS regression and bivariate correlations tested for a mediating effect between human and social capital on rates of re-entry and juvenile arrest rates. Findings indicate neighborhoods with increased rates of returnees have higher rates of juvenile delinquency. In addition, mediating human and social capital indicators affect the direct relationship between re-entry and juvenile crime: neighborhoods with more residents receiving retirement income, higher percent of self-employed residents, non-profit employees, or higher rates of residents earning income above $50 \mathrm{~K}$ had lower rates of
\end{abstract}


returnees in their communities. Greater rates of Portland neighborhoods which house residents with high proportions of house-hold incomes above $50 \mathrm{~K}$ per year see increases in the rate of juvenile crime. Rates of neighborhood churches showed a positive correlation with on both rates of returnees and juvenile crime; obtaining a high school diploma was also associated with increased returnee rates and juvenile crime. Neighborhoods with more residents who are self-employed or employed by non-profit organizations had reduced rates of returnees and juvenile crime. Future research and recommendations are discussed to examine the impact of these findings on neighborhoods with formerly incarcerated persons, levels of human and social capital and juvenile crime in Portland, Oregon. 


\section{Acknowledgements}

Many thanks extend to Drs. Jody Sundt, chair, Brian Renauer and Kris Henning for sitting on my thesis committee and advising me on the pitfalls of data collection, methodology and much more. I especially appreciate the patience and expertise extended to me by all of the professors at Portland State University during the completion of this work and in the class room.

Dr. Sundt has opened my eyes to the ideology, current conditions and operations and policy implications of the penal institution in America. Without her knowledge, I would not have realized the importance of successful re-entry and of streamlining the continuity of care during the transition from incarceration into the community. Her compassion and forethought concerning this topic is unsurpassed and I feel privileged to have a more thorough understanding of what I can do to make a difference in the lives of those incarcerated and their families.

Dr. Renauer has provided me with crucial data sets for re-entry rates and juvenile crime rates for Portland neighborhoods, without which, I would not have been able to complete this project. In addition, he has extended himself above and beyond his duties as assistant professor by agreeing to work and meet with Dr. Sundt and I while on sabbatical. 
I also want to send many thanks to Emma Covelli for extending her knowledge of statistical procedures, without which, I would assuredly be lost. Many thanks for providing me with data sets of church rates for the neighborhoods in Portland, without which, I would not have been able to complete this work.

Thank you to Portland State University for allowing me to further my education and provide me with the opportunity to earn a Master of Science in Criminology. 
Table of Contents

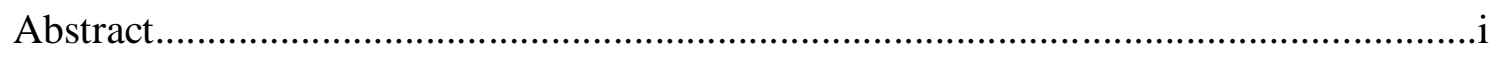

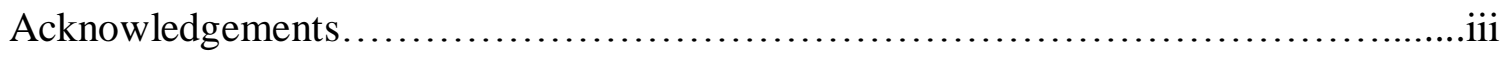

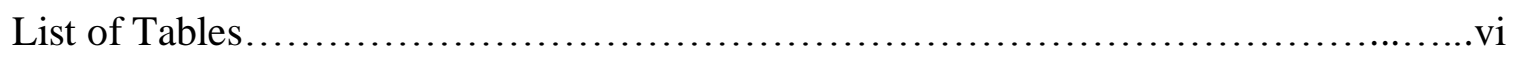

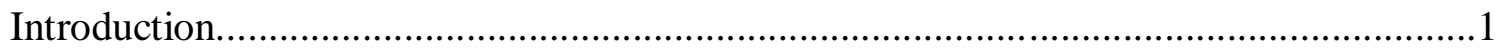

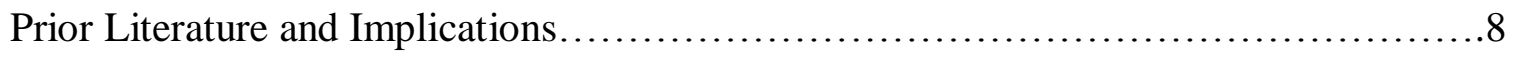

The Creation of Human Capital............................................ 8

Human Capital and the Creation of Social Capital............................11

Negative Human and Social Capital and Crime............................15

Human and Social Capital and Social Reproduction..........................19

Social Capital, the Neighborhood and Incarceration.......................22

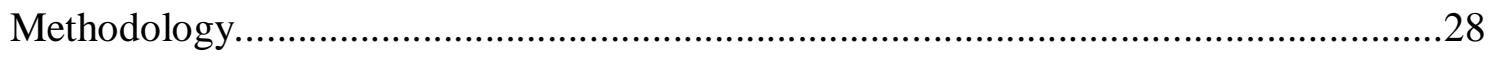

Measurement........................................................ 31

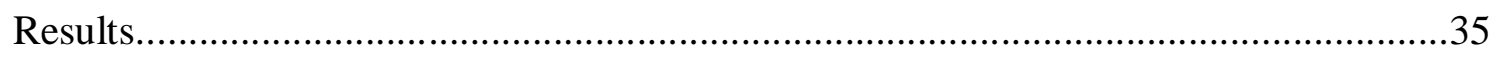

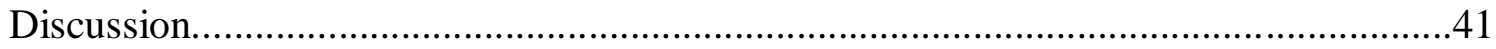

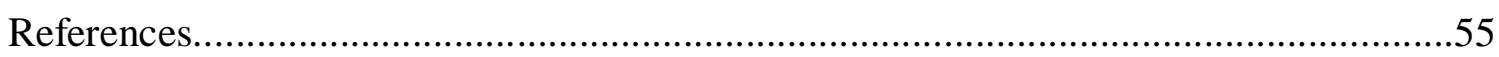




\section{List of Tables}

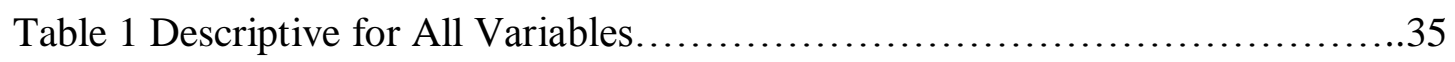

Table 2 Bivariate Correlations Using Pearson's r............................. 37

Table 3 Model 1 OLS Regression for Juvenile Crimes.........................40

Table 4 Bivariate Regression of Slopes for Juvenile Crime and Re-entry............40 


\section{Introduction}

Certain effects of incarceration are arguably more damaging than others.

Concerns for neighborhood effects, community and social cohesion, as well as the increase or decrease of human and social capital, tend to dominate the literature surrounding the economic impact of incarceration on communities. Western, Kling \& Weiman (2000) highlight the importance of studying the effects of the recent trends of incarceration: if incarceration seriously damages the employment prospects of criminal offenders, the massive growth of the prison system will have "a devastating impact on the economic opportunities of minorities and those with little education" (Western et al., 2000, p.2 ). Studies suggest that incarceration is more prevalent among under-skilled minority males. In addition, a large earnings deficit, or employment penalty incurred by incarceration, will deepen racial, educational and economic divides among men (Loury, 1989; Arrow, 1998; Western et al., 2001; Clear, 2001).

Following a seventy year period where incarceration rates were essentially stable, between 1970 and 1999, the rate of incarceration exploded from 96 to 468 per 100,000 (Western et al., 2000). The U.S. prison population grew at its slowest rate (0.2\%) since 2000, reaching 1,613,740 prisoners at the end of 2009 (West et al., 2010). From 2000 to 2008 , the state prison population increased by 159,200 prisoners, and violent offenders accounted for $60 \%$ of this increase (West et al., 2010). White offenders tend to be underrepresented among the prison population: black non-Hispanic males had an imprisonment rate $(3,119$ per 100,000 US residents) that was more than 6 times higher than white non-Hispanic males (487 per 100,000 US residents), and almost 3 times 
higher than Hispanic males (1,193 per 100,000) (West et al., 2010). One in 703 black females was imprisoned, compared to about 1 in 1,1987 white females and 1 in 1,356 Hispanic females (West et al., 2010). An estimation of the percentage of black males that will be incarcerated in their life time, as interpreted from 1991 data by Bonczar and Beck, is $28.1 \%$. In short, we are incarcerating more people today than ever before, and the growth has disproportionately affected people of color.

The importance of human and social capital is far reaching; the ability to acquire skills and sufficient networking abilities allow persons to enjoy elevated levels of economic and social status and avoid stigmatizing events, like incarceration. Human capital refers to education and skill sets, at both the individual and group level, while social capital refers to networks of obligations and reciprocity which allow information to spread between individuals and groups. Human and social capital both produce economic capital through access to relevant skill sets and information about potential employers in the licit labor market (Bourdieu, 1983; Coleman, 1988; Putnam, 2001). However, deficits in either category make entering into the licit labor market difficult; for example, persons with few social connections, a lack of sufficient job skills or a criminal record, may find legal employment hard to attain. If human and social capital levels have been stunted by gaps in educational attainment or absence from the licit labor market, due to incarceration or jailing, relevant job skills and information networks erode, making entrance into licit labor markets increasingly difficult (Clear, 2001).

Acquiring a job depends on access to pertinent information about the availability and working conditions of employment (Ioannidies \& Loury, 2004). Access to such information is heavily influenced by social structures underlying the formation of social 
contacts or social capital; for example, friends and acquaintances who help to build and maintain information networks (Lochner, Kawachi, Brennan, \& Buka, 2003). Information networks, at the individual and group level, are one of the ways that community members increase their ties within and among other community cohorts. These community driven agendas will appeal to certain persons depending on who falls inside and outside the bounds of the community; the result will depend on the creation of new networks of support that tend to influence or undermine efforts to bond within one's personal cohort or to build bridges between other cohorts (Briggs, 1997; Putnam, 2001). Bonding and building bridges are the life blood of information networks and reflects on the overall health of certain neighborhoods (Forrest \& Kerns, 2001; Putnam 2001).

Neighborhood effects of incarceration may transcend pecuniary needs by inhibiting the ability of former inmates to gain access to human and social capital. Human capital is spoken in terms of the quality and quantity of economic skills, and training or education levels, that allow personal skills to add to the flexibility of the worker (Coleman, 1988). Human capital is created by changes the person brings about through the use of skills and capabilities to act in new ways. Because certain jobs require certain skill sets, deficiencies in the amount of human capital can lead to a marginalized job status and return rate, either financial or in more emotive terms such as job satisfaction. In this way, human capital investments can increase the cost of incarceration by the mere fact that inmates are removed from the opportunity to engage in increased skill-building (Lochner, 2004). 
Incarceration is also stigmatizing. Any contact with the prison environment is generally more important than the amount of contact (Schnittker \& John, 2007). Evidence surrounding stigma and incarceration are numerous, linking detrimental effects of incarceration to employment and social support. Inmates are unable to develop normal credentials while in prison, including a work history, marketable skills and social capital; and incarceration itself constitutes a negative credential that is far more difficult to overcome than skill deficit or time spent in the labor force (Schnittker \& John, 2007). Additionally, some employers find indications of incarceration synonymous with unreliability and untrustworthiness, and few are willing to hire applicants with criminal records (Western et al., 2001; Pager, 2003). Accounts of the psychological adjustment of former inmates points to the spread of stigma. Incarceration produces shame and anger within families (Hagan \& Dinovitzer, 1999; Clear, 2001) and undermines trust among close friends (Clear, 2001; Braman, 2004), suggesting a difficult time with social reintegration. Thus, rather than prevent crime, incarceration has the potential to exacerbate it.

Social capital, a building block of social integration, is acquired through changes in people's relationships that tend to facilitate action (Coleman, 1988). Social capital differs from human capital in the way it is acquired. Human capital is conceptualized at the individual level. This individual level emphasizes the addition of new and more advanced skills that allow an individual to contribute more fully to the labor market and help that individual in their quest for material gain. Social capital, however, emphasizes the use of relationships or groups. Here, the locus of control surrounds the community or all the individuals' relationships with others residing in a particular area. In Putnam's 
view, social capital are those "networks and associated norms of reciprocity [that] have value ...for the people who are in them, and they have, at least in some instances, demonstrable externalities, so that there are both public and private faces of social capital" (Putnam, 1995, p.1). Social capital can also be viewed in terms of its form: peer effects, role models, job contacts, norms of behavior, crime, and incarceration (Benabou, 1995). When one is serving their sentence, ties to the outside world are often severed considerably, and in this way, prisoners access to legal economic opportunities is diminished; both human and social capital levels of those incarcerated are decreased (Schmid \& Jones, 2009). Social capital is important not only for its own sake, but also for what one can do with it: how it facilitates the accumulation of other forms of capital (Forrest \& Kearns, 2001).

Human and social capital is reproduced through family relationships, which introduce younger members to networks of social support, thereby enhancing youth with human and social capital levels generationally (Macleod, 1987). As youth are introduced to familial friends and neighbors, social and human capital levels of adults are extended to younger family members, further enhancing the family's human and social capital levels both as the child grows and comes into contact with their own social networks, and while the child is solely dependent upon their parents; inherited human and social capital of both child and adult family members act as resources to attain other forms of capital. When a family member is incarcerated, the incarcerated member's economic contribution is eliminated and the family's economic capital decreased (Clear, 2001). Upon return, the economic contribution of the formerly incarcerated family member is severely limited, 
due to depletion of human and social capital while incarcerated, resulting in limited social networks to exchange information with and gain access to employment (Western et al., 2000). In addition, stigmatization of the family incurs both with the removal and return of formerly incarcerated persons, has negative affects on juvenile educational attainment and emotional development. "Children experience developmental and emotional strains, have less parental supervision, are at greater risk of parental abuse, and face an increased risk of having their own problems with the criminal justice system" (Clear, 2001, p.105).

In sum, our general research question is: will human and social capital levels of a neighborhood to which former offenders return serve as a buffer to insulate it against increased juvenile crime rates? We will be assessing Portland neighborhoods in terms of the amount of human and social capital measures found therein; these measures are individual levels of human and social capital aggregated to the neighborhood level. The purpose of this study is to test the relationship between aggregate neighborhood levels of re-entry rates and human and social capital measures on the rates of juvenile delinquency in neighborhood settings, while controlling for race. The independent variable, re-entry rates, will generally be defined as the numbers of persons returning to neighborhoods from an incarcerated setting. Re-entry rates will also symbolize an aggregated measure of human and social capital levels of the formerly incarcerated. Human capital will generally be defined as individual skill sets, which include job skills, training and education level an individual may utilize in the creation of economic capital and is thought to mitigate the effects of re-entry rates on the rates of juvenile crime. Social capital will generally be defined as networks of reciprocity that facilitate the transference 
of information, and is thought to mitigate the effects of re-entry rates on juvenile crime. The dependant variable, rate of juvenile crime, will generally be defined as the number of arrests of persons under the age of 18 in a given neighborhood. The control variable is race, or the proportion of non-white neighborhood residents. 


\section{Prior Literature and Implications}

\section{The Creation of Human Capital}

Human capital theories suggest economic market success is highly influenced by returns on investments in education and training (Becker, 1968). These investments have a capacity to transform the productivity of an individual that is analogous to the use of tools, money or machinery (Mc Carthy \& Hagan, 2001). Education and training can transform individual aptitudes for successful returns in the labor market. According to Becker (1968), one of the most important contributions to human capital analysis is its distinction between general and specific skills, and the recognition that specialization of skill equates to an increase of human capital. Human capital can be applied more generally to encompass broader notions of skill acquirement that reflects more basic needs of the labor market at a macro level. Human capital also reflects an increased investment in the specialization of certain skills through the use of furthered education and training, which allow greater returns from the labor market than more generalized skill sets.

Human capital literature emerges from Becker (1964, 1967), Ben-Porath (1967) and Mincer (1974). According to human capital theory, increases in a person's amount of knowledge or human capital, raise the productivity of that person in the marketplace. Raises in the marketplace of economy allow individuals to produce monetary earnings; in the nonmarket place or household, a person produces commodities that correspond with utility function (Grossman, 2000). To realize potential gains in productivity, individuals have an incentive to invest in on-the-job training and formal education. The costs of these 
investments include direct outlays on market goods and the opportunity cost of formal education and training, time that must be withdrawn from competing uses (Grossman, 2000). This framework was used by Becker (1967) and Ben-Porath (1967) to develop models that determines the optimal quantity of investment at any age; such quantities tend to vary over the life course of an individual and among individuals of the same age (Grossman, 2000).

The Becker and Ben-Porath model is important because it allows researchers to quantify the likelihood of acquiring sufficient human capital by age. Such quantification directly relates to individual incentives, which inform individual decisions concerning the ability to secure licit and illicit labor market activities with the least amount of effort. If human capital levels are sufficient, persons will not view on-the-job-training or formal education as competing with other demands on their time. Rather, these activities will be seen as an investment in human capital or an investment in acquiring desirable employment. However, if human capital levels are not sufficient, such training will be viewed as a burden, inducing persons to invest their time in other activities which produce economic capital; for example, entering into the illicit labor market.

Incentives have explanatory power in determining why people do what they do. However, incentives can only predict future behavior, whether it occurs or not is measured by self-report surveys or direct observation. Lochner (2004) advances a more comprehensive framework about the relationship between age, education, crime and human capital through the administration of several surveys designed to target selfreporting of criminal activity, education and age. Lochner found dramatic differences in 
property and violent crime across education groups. This pattern suggests that education and training increase human capital and market wages, which raises the costs of planning and participation in crime. Human capital investments also increase the costs associated with incarceration because they increase the value of time served in the furtherance or maintenance of a person's human capital. For crimes that require little market skilllarceny, assault, and drug dealing, a human capital approach suggests that both age and education should be negatively correlated with crime in adults (Lochner, 2004). Market skills may increase incentives to engage in highly skilled forms of crime, including embezzlement, forgery and fraud, because the increased skill set allows a higher return of benefits in the criminal market structure.

Models from Becker and Mc Carthy assume that skills can only be developed through costly time investments, education and job training, and that skills developed will enhance the return of engaging in licit employment. However, market skills may or may not raise the net return of illicit market participation. Lochner (2004) goes a step beyond his predecessors when he combines the idea of market returns with specific investment choice: individuals optimally choose how much time to allocate to the investment of human capital, legitimate work and crime. Individual choice is imperative to the understanding of how someone maximizes their investments in each of the market areas, licit or illicit. If someone chooses to engage in crime, they will face the possibility of incarceration. If individuals become incarcerated, they are provided limited activities of consumption and they cannot invest, work, or engage in crime again until their release 
(Lochner, 2004). Accumulation of human capital is seen in terms of individual capacity for learning, the time invested in skill building, and criminal ability.

Lochner (1999) formalizes a crime model that yields a declining age-crime profile once work begins, as long as human capital rates do not decrease over the life span. This occurs due to the stable nature of the returns of crime, while the returns from work tend to fluctuate in correspondence with a person's level of human capital. Tendencies of market returns from street crimes have minimal effects based upon prior criminal activity, or market skills of criminality. Most street criminals are of low ability, education and are very young, suggesting that general and especially specialized market skills are substantially lower in the criminal market when compared to the licit labor market (Lochner, 1999).

\section{Human Capital and the Creation of Social Capital}

Human capital is formed through increased amounts of time devoted to enhancing general and specialized market skills. Social capital focuses not on skill sets that individuals maintain or enhance, but on the relations that individuals have to one another in their communities. The value of the assessment of social capital lies in that it identifies certain aspects of the social structure by their functions (Coleman, 1988), linking communities with differences in social capital to communities with differences in crime and incarceration rates (Western et al., 2000; Clear, 2001). The identification of these processes is most attributed to the works of Bourdieu, Coleman and Putman. 
Bourdieu explains social capital's importance by beginning with a definition of capital: "capital is accumulated labor which, when appropriated on a private, i.e. exclusive, basis by agents or groups of agents enables them to appropriate social energy in the form of reified or living labor" (Bourdieu, 1983, p.183). This principle underlies notions of market and social norm regulation inherent in market functions. There are three forms of capital according to Bourdieu: economic, cultural and social. Economic capital refers to capital that is immediately and directly convertible to money and maybe extended into the formation of property rights. Cultural capital refers to the conversion of capital into economic capital and maybe institutionalized into education requirements (Bourdieu, 1983). Social capital is made up of obligations or connections that are convertible into economic capital and maybe institutionalized into forms ranging from title of nobility (Bourdieu, 1983) to criminal underclass.

Social capital relations exist in the practical state, in material and/or symbolic exchanges that help maintain them. They are also applied to proxciminal notions: relations between individuals exist within close proximities of individuals, usually referred to as communities or neighborhoods (Ioannidies \& Loury, 2004), but can also include prison social cohorts. The volume of social capital at someone's disposal depends in large part on the nature and extent of that person's social network and how likely those networks are to produce effects, either in information exchanges, product acquirement or civic engagement. Social capital requires an investment in social underpinnings that facilitate friend acquirement and maintenance (Bourdieu, 1983). Social networks reflect a product of social capital. The process of attaining social capital is reflected and 
reproduced in exchanges, which encourages and produces mutual knowledge and recognition (Bourdieu, 1983).

Coleman defines social capital by its function. Social capital is seen as existing in many forms of interactions and exchanges with two major components in common: "they all consist of some aspect of social structures, and facilitate certain acts of actors within the structure" (Coleman, 1988, p.98). Social capital accumulation adheres to the structure of the relations between and among actors. The value lays in using aspects of the social structure as resources an individual has at their disposal to achieve their interests. This value allows the recognition that certain interactions produce value to the individuals directly involved and to higher vertical structures of social capital, namely the neighborhood. This value is rooted in social organization (Coleman, 1988).

Formations of social capital depend upon two key elements: trust and the extent of obligations that are held. Trust refers to the belief that obligations will be repaid. Social structure differs in both instances of trust and obligations, and the actor's behavior within the former structure will differ in the second. Differences may arise for a variety of reasons: variances lie in the actual needs that person has for help, in degrees of affluence, in cultural differences and in the closure of social networks (Coleman, 1988). No matter the source, individuals with more outstanding obligations at any time have more social capital to draw from, regardless of their incarceration status.

The notion of closure is extremely important to the formation of social capital. For Coleman, closure is a necessary but not sufficient condition for the emergence of 
effective social norms is "action that imposes external effects on others" (Coleman, 1988, p.105). Norms are formed as attempts to limit negative external effects and encourage positive ones. In a social structure that includes closure, individuals are held accountable for their actions or their return of obligations (Ioannidies \& Loury, 2004). Individuals in these structures provide collective sanctions on behavior they feel is adverse to the collective good. Individuals exert this influence upon each other because each person in the cohort is directly tied with its other members. These groups can be said to form strong ties. Social cohorts without closure are those whose members have formed weak ties or people are related to each other on a superficial basis (Forrest \& Kearns, 2001; Ioannidies \& Loury, 2004). Weak ties are said to outnumber strong ties by 3:1 (Forrest \& Kearns, 2001).

Putnam defines social capital as "features of social organization such as networks, norms and social trust that facilitate coordination and cooperation for mutual benefit" (Putnam, 2001, p. 12). Notions of bonding and bridging are used to illustrate how social capital is not exclusively homogeneous; it exists in close relations of individuals and can be used to draw on other facets of one's extended communities. Bonding refers to the links between like-minded persons and in this aspect, social capital can be said to be homogeneous. Bridging refers to the links between the building of connections between heterogeneous groups (Carroll \& Stanfield, 2003). Bridging is frailer, mainly because it is rooted in weak social tie formations, but dramatically enhances social inclusion. However, social capital does facilitate informal contract enforcement (Putnam, 2001). This logic is derived from game theory (Putnam, 2001; Ioannidies \&Loury, 2004). One 
thought underlying game theory is: If I have dense ties and networks of reciprocity with others, then I don't have to engage in the formal contract formation with my neighbor (Putnam, 2001). Persons assume that others will attend to the norms surrounding notions of neighborliness, and a more informal contracting process occurs that facilitates both individual's needs (Ioannidies \& Loury, 2004). Social networks are said to change over time in accordance with the community member's welfare needs and changes (Woolcock \& Narayan, 2000). The costs and benefits of engaging in social capital functions lies in the eyes of the beholders, something may have little cost association now, but that cost may increase and the ratio will have to be reevaluated.

\section{Negative Human and Social Capital and Crime}

Human and social capital are often glamorized, including the relevance of only positive human and social capital. However, both forms of capital can have a negative relationship within and among social cohorts, often leading to neighborhood disorganization (Kawachi, Kennedy \& Wilkinson, 1999) and lower levels of collective efficacy (Lochner, Kawachi, \& Kennedy, 1999; Lochner et al., 2003; Ioannidies \& Loury, 2004). Those same mechanisms that are involved in the creation and maintenance of positive human and social capital are involved in the creation and maintenance of negative human and social capital. One accumulates negative human capital through education and training of criminal activity (Putnam, 1995; Lochner, 1999; Western et al., 2000; Mc Carthy \& Hagan, 2001; Lochner, 2004). Illegal income is advanced by previous offending, prior arrests, conviction and probation (Mc Carthy \& Hagan, 2001). Research effects of criminal human capital point to the need of specialization of criminal 
skill sets. Exclusive drug dealing tends to produce increases in illegally obtained financial resources (Mc-Carthy \& Hagan, 2001).

Ehrlich (1973) poses a cost-benefit relationship towards the accumulation of criminal human capital and the possibility of engaging in crime. His central hypothesis states "if, in a given period, the two activities [criminal/noncriminal activity] were mutually exclusive, one would choose between them by comparing the expected utility associated with each alone" (Ehrlich, 1973, p.523). Participation in the criminal market is a result of optimizing an individual response to incentives manifest in the forms of licit/illicit activity (Mocan, Billups \& Overland, 2000) There is a standard assumption: persons are risk adverse (Mocan et al., 2000). Risk adversity underlies notions of the nature of cost-benefit analyses to engage in market activity in any form. Risk aversion tends to decrease with increased income, resulting in an increase of unemployment rates leading to a decrease in crime (Mocan et al., 2000). Stemming from the absolution of risk, someone that is unemployed and plans to engage in the labor market will have less time to engage in the criminal labor market because of the time investment in locating and securing employment (Mocan et al., 2000). "The acquisition of firm specific human capital, internal labor markets in large firms, public sector pay schedules and union seniority provisions ensure job continuity and earnings growth for young men" (Western et al., 2000, p.5). Increases in human capital tend to reduce property crime by raising its opportunity costs (Lochner, 1999). However, the opposite can be true if one chooses to enter into the criminal labor market. Unemployment in this instance would tend to 
increase the time available to acquire more specialized criminal skill sets (Lochner, 1999).

Criminal social capital is formed through relationships someone has with others engaged in the criminal labor market. Inner city youth gangs are said to comprise very high levels of criminal social capital (Carroll \& Stanfield, 2003). Criminal social capital is reinforced through the affiliation and use of social networks that provide gang members an inside track to increased knowledge and obligations of reciprocity that lend to increased participation in crime (Putman 1995; Carroll \& Stanfield, 2003). Criminal social capital tends to increase the potential for more crime and violence when it is concentrated in particular groups, gangs, ethnic clans, and close neighborhoods, and is not disseminated throughout society (Lederman, Loayza \& Menendez, 2002). Cohesion in these groups exacerbates the tensions between them and increase society's overall violence (Lederman et al., 2002). In other words, increased group identity may promote intergroup hostility (Lederman et al., 2002).

Recent studies indicate four negative consequences to social capital: exclusion of outsiders, excess claims on group members, restrictions on individual freedom and downward leveling norms (Portes, 1998). Exclusion to outsiders is generated through extremely strong ties between individuals in a cohort. Social capital generated by bounded solidarity and trust are at the core of the cohort's economic advance, but also decrease trust among other cohorts. Bridging networks have no chance to form and the lack of trust towards outsiders causes more tension or action (Putnam, 1995; Portes, 1998). 
Closure lies at the heart of excess claims on group members. Social cohorts that include high levels of closure tend to also have free rider problems. Collective action is taken when one fails to meet their obligations, less diligent members enforce on more diligent members increased demands based on those shared norms that bond the group together so tightly (Portes, 1998). Levels of social control are strong in cohorts that exhibit large levels of social capital. Levels of social control can restrict certain forms of expression amongst members. Tightly knit cohorts tend to stifle individual freedom and influence less diligent members to align themselves with another cohort (Portes, 1998).

Situations exist where cohort members bond to each other because of a common adverse societal experience or attitudes that oppose mainstream society (Portes, 1998). Individual success stories in these cohorts tend to undermine group cohesion and results in the downward leveling of group norms; for example, persons who are involved with the criminal justice system tend to have lower aspirations for economic employment than those who are not involved with the criminal justice system. Persons who buck the odds and find higher quality employment while also being involved in the criminal justice system would not be said to have a downward leveling of group norms, they are the success stories. These norms can enhance the cost-benefit analysis of acquiring criminal human and social capital while simultaneously operating to keep the cohort in one place, forcing more ambitious to escape (Portes, 1998). 


\section{Human and Social Capital and Social Reproduction}

Social and human capital levels exist to assist people in their accumulation of economic capital (Bourdieu, 1983; Putnam, 1995; Coleman, 2001). Regardless of the type of social and human capital acquired, either in the traditional sense or in its negative counterpart, the transformation of such capital into economic capital helps to secure goods or services people depend on in their day-to-day lives. Economic capital is transferred across generations; for example, in the form of a last will and testament. Social and human capital is also transferred generationally (Bourdieu, 1983; Putnam, 1995; Coleman, 2001).

Bourdieu conceptualizes social capital as a process by which individuals in the dominating class, by mutual recognition and acknowledgement, reinforce and reproduce a privileged group which holds various types of capital- economic, cultural and symbolic (Lin, 1999). Nobility and titles are good examples of such a reproductive cycle where economic, human and social capital levels are transferred to the next generation through closure functions, manifested in trust and obligation returns. However, intergenerational or intra-familial gang membership provides another good example of social reproduction accompanied by closure functions. Social capital utilized in this sense is a way of maintaining and reproducing dominant class structures. A denser social network, one which includes large amounts of bonding, would be more likely to promote the sharing of resources which, in turn, maintain group or individual resources (Lin, 1999). Some have characterized this theoretical position that views social capital as class goods (Lin, 1999). 
Implications of Bourdieu's social capital reproduction theory illuminate how levels of such capital are transferred to some social groups, but not others. Neutral academic standards, such as standardized testing, are laden with culture class resources, which reflect the dominant class interests (Akom, 2008). Working and lower class students must acquire the social, lingual and cultural competencies of the middle classes (Akom, 2008). Those born into the middle class inherit such competencies by virtue of their birth and subsequent socialization by the dominant class. Working and lower class students are penalized in the acquisition for academic credentials due to information poverty (Akom, 2008); “the poor and working class students are systematically denied forms of social and cultural capital that are recognized as signs of intelligence by schools" (Rose, 1989, p. 6). Because differences in academic performance are normally explained by merit deficiencies of individuals or intellectual abilities and cultural and social resources transmitted through family structures, differences in privileges between upper and lower class students are legitimized by academic credentials, and translated back into economic capital through labor market functions, which honor the credentials learned by the dominant classes (Macleod, 1987).

Coleman and Putnam see social capital as a collective asset instead of a collective deficit dependent upon birth circumstances. Coleman maintains that social capital consists of social structural resources that are useful to individuals for specific actions; such features are also useful in terms of collective assets (Lin, 1999). In this sense, social capital is a collective good, available to all members of a social network regardless of its utilization, contribution or promotion by social group members (Lin, 1999). Because 
social capital is a public good, it depends on the good will of individual members to make an effort not to be free riders. Thus, norms, trust, sanctions, authority and other structural features become important in sustaining social capital. In this conceptualization of social capital, open networks would be more likely to access advantaged positions and resources, through bridging mechanisms, which, in turn, enhance the opportunity to gain additional resources (Lin, 1999).

Social reproduction mechanisms help explain another adverse consequence of incarceration: decreased ability for incarcerated parents to transfer economic capital to their adult children upon their deaths. One of the most prominent consequences of incarceration is the deterioration of economic family functions (Clear, 2001). Financial hardships abound due to a partner's removal from the home and the loss of their economic contribution. Because most families with incarcerated members are financially limited to begin with, even small economic losses can be devastating (Clear, 2001).

Families also connect one another, especially children, to networks of social supports that become the foundation for later social capital as adults (Clear, 2001). When members of households are removed due to incarceration, there are negative consequences for the partner and children who remain (Bloom, 1995; Harriston, 1998). An incarcerated adult family member has been shown to be a source of many problems, one of which is juvenile delinquency (Windom, 1994). Studies show that children and partners of incarcerated adults tend to experience other difficulties which include problems in school, depression, anxiety, low self-esteem and aggression (Hagan \& Dinovitzer, 1999). When a formerly incarcerated family member returns from prison, 
additional familial difficulties abound, including role adjustments for parent-child, childparent, and spouse-spouse norms and associations (Clear, 2001).

\section{Social Capital, the Neighborhood and Incarceration}

Social capital is the concept of a sense of community (Lochner et al., 1999). A related concept is neighboring and neighborhood cohesion. Neighboring involves social interactions where residents establish social connections at personal or neighborhood levels (Lochner et al., 1999). Neighborhoods are forms of social organization. An organization can be brought into existence for one set of purposes and can also be appropriated for other uses, constituting social capital (Lochner et al., 1999). The social organization approach views communities in terms of social systems or networks, as well as formal and informal associations rooted in family life and ongoing socialization processes (Kawachi, Kennedy \& Wilkinson, 1999). Social disorganization is defined as the "inability of a community structure to realize the common values of its residents and maintain effective social controls (Kawachi et al., 1999, p.721).

A growing number of studies support the link between low levels of social capital and crime rates. Kawachi et al. (1999) examine the effects of levels of social disorganization, social capital and participation in crime. Using measures of violent crime, homicide, rape, robbery and assault, and property crime, burglary, larceny and theft, Kawachi et al. (1999) found indicators of deprivation are correlated with reduced levels of social capital. Higher poverty and unemployment rates manifested decreases in trust among community members (Kawachi et al., 1999). Higher educational attainment 
has an inverse relationship with crime participation (Kawachi et al., 1999). Lochner et al. (2003) concluded that adjusting for neighborhood deprivation, indicators of social capital showed inverse relationships to death rates from all causes. Measures used to assess social capital include: reciprocity, trust and civic engagement; all death causes include natural and unnatural deaths.

Lederman et al. (2002) concludes the growth rate of Gross Domestic Product per capita is a robust determinant of homicide rates; trust shows a negative relationship to homicide rates; church membership present a negative coefficient, and the coefficients associated with variables of membership and participation in voluntary social organizations do not change signs or statistical significance. Kennedy, Kawachi, Prothrow-Stith, Lochner and Gupta (1998) hypothesize "a highly visible gap in the distribution of income may give rise to social disorganization and low social cohesion, as indexed by the level of mistrust among members in society, as well as their propensity to associate with each other" (p. 15). Kennedy et al. (1998) found a strong relationship between income inequality and incidence of homicide and violent crime via the depletion of social capital. These studies tend to corroborate the connection between social disorganization and decreases in social capital, which leads to increases in crime.

Levels of social disorganization have an impact on incarceration rates. Individuals are likely to return to those communities where the offense was committed. The numbers of released inmates will mount over time, and a prison record will become an increasingly common feature of the community (Western et al., 2000). "The sheer volumes of individuals moving into and out of prison can dramatically alter the 
conditions of supply and demand in local labor markets" (Western et al., 2000, p. 7). The immediate impact of withdrawal or incarceration, reduces labor supplies and improves prospects for individuals not incarcerated. When former inmates begin the reentry process, however, they will augment the supplies of the disadvantaged workers, confined to secondary labor markets, and have the opposite effects (Western et al., 2000). Over longer time periods, the concentration of released inmates in certain communities could affect decisions about where to locate businesses and further reduce labor demands (Western et al., 2000; Clear, 2001).

The introduction of more former inmates back into the community alters community norms and networks, and reinforces former inmate's limited attachments to the licit labor market (Western et al., 2000). Upon release, former inmates establish their involvement in criminal social capital cohorts and reestablish ties made with other former inmates while incarcerated. The creation of these new criminal cohorts provides access to increase each individual's criminal human capital and these cohorts also increase obligations and information concerning illicit activities, and increase criminal social capital. If there are more benefits to engage in the illicit labor market, criminal activity rises as a result. Engaging in criminal activity increases the propensity to be arrested, prosecuted and incarcerated- the cycle continues. 


\section{Research Strategy}

Several hypotheses can be developed from current understanding of how someone acquires human and social capital, and the relationship between social reproduction, social disorganization and increased crime rates. The potential for the creation of criminal human capital can be assessed in terms of an individual's ability to acquire specialized licit market skills. If individuals do not have access to education and training, the costbenefit relationship of entering into licit markets may be too high, resulting in the entrance into illicit markets. If individuals choose to enter into illicit markets, they will also enter into criminal social capital cohorts, thereby increasing their criminal human and social capital. As individuals engage in criminal social capital cohorts, such participation will lead to increases in violent crime across other cohorts. This cross cohort infection will lead to higher levels of distrust amongst community members and tend to erode social organization, causing social disorganization levels to rise. Levels of social disorganization lead to increases in violent crime, arrest and prosecution rates, and eventually to incarceration. Inmates who successfully serve their sentences will be released from prison into the neighborhoods where they committed their imprisoning offense; formerly incarcerated persons' levels of human and social capital will decrease as a result of their incarceration. Aggregated neighborhood levels of human and social capital serve as potentially mitigating influences between the numbers of former inmates returning to their neighborhoods and neighborhood rates of juvenile crime. However, deficits in aggregated human and social capital at the neighborhood level will aggravate neighborhood rates of juvenile crime as former inmates re-enter into the neighborhood, as 
human and social capital measures of former inmates are transferred to their children through the social reproduction process.

This study can help us understand the needs of Portland neighborhoods by furthering knowledge about which neighborhoods formerly incarcerated individuals return to. Evidence from 2000 suggests that some Portland neighborhoods experience higher numbers of returning formerly incarcerated persons than others; "the numbers of releases ranged from 0 to 110 per year $($ mean $=8.56)$; release rates varied from 0 to 37.45 (mean $=1.69)$; seventy-seven Portland neighborhoods had at least one release" (Renauer, Cunningham, Feyerherm, O’Connor \& Bellatty, 2006, p. 367). Evidence also suggests that returning formerly incarcerated persons choose to reside in some Portland neighborhoods and not others. "Approximately 77 percent of the variance in the rate of returning formerly incarcerated persons is explained by the rate of social services, churches, percent of low cost housing, and concentrated disadvantage" (Covelli, 2008, p. 28). Findings predict that low-cost housing, not social services or churches, provide greater predictive power about where formerly incarcerated persons choose to reside during re-entry. Neighborhoods that provide higher rates of social services and have levels of concentrated disadvantage also have higher rates of returning formerly incarcerated persons. However, Portland neighborhood levels of human and social capital are unknown. If human and social capital theories are correct, these omitted variables could help improve formerly incarcerated persons' re-entry process and aid in desistance from adult crime and juvenile crime of their children or other children in the 
neighborhood. This research also provides insight into the effect of re-entry on human and social capital.

Portland boasts numerous services to assist those in the transition from incarceration to the community. Services include traditional state funded organizations such as Multnomah County Department of Community Justice- Transition Services Unit (TSU), which coordinates with each detention center and helps link recently released offenders to services including prerelease planning, case management, housing, transportation, and medical and benefit assistance, as well as unconventional service providers. For example, Portland Partners Re-Entry Initiative (PPRI) assists with preemployment training, career exploration and planning, access to vocational training and education programs, support services, and mentoring. All Portland service providers will benefit from understanding the impact of human and social capital levels of the neighborhoods to which former offenders return because such indicators will allow providers to further curtail services to provide a more holistic view of the conditions of re-entry. In addition, studying human and social capital indicators of Portland neighborhoods will allow cities with similar demographic, incarceration, re-entry rates and re-entry service providers to provide the most comprehensive re-entry plan to aid in crime desistance in adults and halt social reproduction processes leading to juvenile delinquency. 


\section{Methodology}

Data for returning formerly incarcerated persons, census, education, employment, income and crime rates are all aggregated by the neighborhoods of Portland, Oregon, which includes a total of 92 neighborhoods. Portland, Oregon receives more returning formerly incarcerated persons than does any other city or county in Oregon (Oregon Department of Corrections, 2007).

\section{Sources of Data}

Oregon Department of Corrections (DOC) release data, 1997-2002. Data from the Oregon DOC was obtained, listing the addresses of all state detained returning former inmates for the years of 1997 to 2002. A total of 10,404 state releases to Portland or Multnomah County occurred during the years of 1997 to 2002. Twelve hundred and fiftyfive of these releases were removed from the data because the addresses were located outside of the Portland area or the individual was released to another correctional facility. Ninety-four released individuals were removed from the analysis because they were detained by immigration or were facing the possibility of deportation. Another 1,390 of the releases had missing, incomplete or otherwise unmappable addresses. A total of 7,695 Portland release addresses were retained in the data set and mapped to the 92 neighborhoods of Portland. Release data represent decreases in human and social capital of formerly incarcerated individuals; aggregated rates of release represent neighborhood level human and social capital indicators of returnees.

Unified Crime Report (UCR) juvenile arrest data, 2006-2008. Data from the UCR was obtained from the Portland Police Department, listing the numbers of juvenile arrests 
for the years of 2006 to 2008 . A total of 19,952 juvenile arrests were reported to the police over this two year period in the city Portland. Juvenile arrest data was selected to eliminate any possible incarceration effect, which may result from adult arrest, prosecution or incarceration.

Neighborhood Human Capital Measures, 2000. Listings of neighborhood human capital measures was taken from the 2000 Portland neighborhood census data, with a total of 92 neighborhoods. The following human capital measures were obtained by the 2000 US Census: 1) high school graduation rates, 2) house-hold income, and 3) employment type. Indicators were chosen to represent the most pertinent factors contributing to human capital levels based on theory considerations.

Neighborhood Social Capital measures, 2000. Listings of neighborhood social capital measures was taken from the 2000 Portland neighborhood census data, with a total of 92 neighborhoods. The following social capital measures were obtained by the 2000 US Census: 1) the number of residents employed by non-profit businesses 2) the number of residents self-employed, and 3) the number of churches. Indicators were chosen to represent the most pertinent factors contributing to social capital levels based on theory considerations.

Proportions of neighborhood residents employed in the non-profit sector were chosen to represent opportunities for employment for neighborhood residents, unemployed or unsatisfactorily employed, elicited from those employed in the non-profit sector. Residents choosing to act on such information are thought to form obligations of 
reciprocity with those spreading information. Non-profit sector employees also represent a measure of reciprocity at the neighborhood level; non-profits operate to increase quality of life and resources of community members without reaping profits, which in turn, may inspire neighborhood residents to volunteer, returning obligations for neighborhood improvement.

The numbers of self-employed residents was chosen to represent information spread about a more unconventional form of employment, its attainment and sustainment; residents choosing to act on such information are predicted to form obligations of reciprocity with those spreading information. Neighborhood rate of churches was chosen to illustrate support services and bonding and bridging functions of social capital; churches are involved in fundraising, provide alcohol and drug treatment programs and link neighborhood members with one another, which may also provide an indirect measure of network building capacity.

Neighborhood church data, 2002. A nondenominational listing of Portland churches during the year 2002 was obtained from three different sources to increase the integrity of the data set. These sources are: 1) 2001 to 2002 phone book listings of churches (Qwest, 2001), 2) Mission Portland online directory (Mission Portland, 2007), and 3) Need Help online Christian directory (Need Help, 2007). Church listings were obtained from all sources and consolidated into one data base; church listings were verified for existence via telephone or 2001 to 2002 phone book. Seven churches were verified to exist in 2002 , however their addresses at that time was unverifiable, justifying their exclusion. An additional 59 churches were excluded because they reside in 
neighborhoods where no human and social capital variables were obtained. A total of 492 churches were retained in the data set and mapped to the 92 Portland neighborhoods.

US Census data, 2000. The following demographic and neighborhood information was obtained from the 2000 US Census: 1) neighborhood population counts, 2) race composition, and 3) ethnic composition.

Measurement

Neighborhood rate of returning formerly incarcerated persons. The independent variable, neighborhood rates of returning formerly incarcerated persons, was calculated as the average yearly number of releases per 1,000 residents in the neighborhood. The number of returning offenders to a neighborhood ranged from 0 to 788 , with a mean of $83.64(\mathrm{SD}=121.89)$. The neighborhood rate of returning formerly incarcerated persons ranged from 0 to 270.23 , with a mean of $15.30(\mathrm{SD}=30.50)$. The re-entry data was fairly skewed. Calculating the natural log of this variable greatly improved the normalcy of the data.

Neighborhood rate of juvenile arrests. The dependant variable, neighborhood rate of juvenile crime, 2006-2008, was calculated as the average number of reported offenses per 1,000 residents in the neighborhood. The neighborhood rate of juvenile arrest includes curfew, runaway, arson and vandalism reports. The number of neighborhood juvenile reported offenses ranged from 0.1 to 0.71 , with a mean of $0.05(\mathrm{SD}=0.08)$. The neighborhood rate of juvenile reported offenses ranged from 4.44 to 714.29 , with a mean 
of $49.56(\mathrm{SD}=81.51)$. The juvenile crime data was fairly skewed. Calculating the natural log of this variable greatly improved the normalcy of the data.

Neighborhood rate of high school graduates. A human capital variable, neighborhood rate of high school graduates ranged from 22.09 to 268.53 per neighborhood.The neighborhood rate of high school graduates was calculated as the total number of actual high school graduates per 1,000 neighborhood residents. This variable does not include any education acquired above a high school graduate certificate.

Neighborhood rate of house-hold income. A human capital variable, house-holds earning $50 \mathrm{~K}$ per year or more represents neighborhood economic resources. The number of neighborhood residents with household income above 50K ranged from 0 to $1,723.64$. The neighborhood rate of house-hold income above 50K ranged from 0 to 176.26 . The neighborhood rate of house-hold income was calculated by the total number of income per 1,000 neighborhood residents.

Neighborhood rate of retired residents. A human capital variable, the number of retired neighborhood residents ranged from 0.03 to 0.11 , with a mean of $0.06(\mathrm{SD}=$ 0.02).. The neighborhood rate of retired residents ranged from 30.61 to 142.95 , with a mean of $61.59(\mathrm{SD}=21.77)$. The neighborhood rate of retired residents was calculated by the total number of retired per 1,000 residents.

Neighborhood rate of residence receiving government assistance. A human capital variable, the number of neighborhood residents receiving government assistance ranged from 0.06 to 0.35 , with a mean of $0.12(\mathrm{SD}=0.05)$. The neighborhood rate of 
residents receiving government assistance ranged from 0 to 65.99 , with a mean of 16.58 $(\mathrm{SD}=11.09)$. The neighborhood rate of residents receiving government assistance was calculated by the total number of retired per 1,000 residents.

Neighborhood rate of non-profit business employees. A social capital variable, numbers of non-profit business employees ranged from 1.21 to 916.76 , with a mean of 288.01 ( $\mathrm{SD}=221.26)$. The neighborhood rate of non-profit business employees was measured as the number of non-profit business employees available given the neighborhood population size. This variable was calculated by the total number of nonprofit business employees in a neighborhood per 1,000 neighborhood residents. The neighborhood rate of non-profit businesses employees ranged from 7.02 to 110.39 , with a mean of $53.64(\mathrm{SD}=20.85)$.

Neighborhood rate of self-employed residents. A social capital variable, the number of self-employed residents ranged from 1.42 to 652.56 per neighborhood. The neighborhood rate of self-employed residents was measured as the number of selfemployed residents available given the neighborhood population size. This variable was calculated by the total number of self-employed residents in a neighborhood per 1,000 neighborhood residents. The neighborhood rate of self-employed residents ranged from 11.37 to 94.52 .

Neighborhood rate of churches. A social capital variable, numbers of churches ranged from 0 to 18 , with a mean of $5.35(\mathrm{SD}=4.72)$. The neighborhood rate of churches was measured as the number of churches available given the neighborhood population 
size. This variable was calculated by the total number of churches in a neighborhood per 1,000 neighborhood residents. The neighborhood rate of churches ranged from 0 to 4.55 , with a mean of $1.01(\mathrm{SD}=0.87)$. 


\section{Results}

The descriptive statistics for all variables are shown in Table 1. The distribution of the neighborhood rate of formerly incarcerated persons and juvenile crime rates were fairly skewed. A natural logarithmic transformation of the data was applied to the dependant variable (juvenile crime rates) and re-entry rates, which greatly improved the normalcy of the data. Bivariate correlations between human and social capital variables, re-entry rates and juvenile crime rates are presented in Table 2. All of the descriptive, correlations, screening for outliers and mulitcollinearity, and analysis were conducted using SPSS. There were no missing values in the data set. Due to mulitcollinearity issues, low-skilled and high-skilled employment, post high school graduates and government employees were excluded from the multivariate model.

Table 1

Descriptive Statistics for All Variables: Rates per 1,000 Residents

\begin{tabular}{lrrcc}
\hline & Mean & S.D. & Skewness & Kurtosis \\
\hline Re-entry & 2.08 & 1.14 & -0.12 & 0.97 \\
Juvenile Crimes & 4.76 & 1.31 & -0.75 & 0.17 \\
Non Profit Employees & 53.64 & 20.85 & 0.20 & -0.18 \\
High School Graduates & 139.05 & 58.39 & -0.01 & -0.70 \\
Self-Employed Residents & 44.87 & 17.14 & 0.76 & 0.40 \\
Churches & 1.01 & 0.87 & 1.70 & 3.80 \\
House-hold Income, & 857.80 & 607.94 & 0.82 & 0.32 \\
50K+ & & & & \\
Government Assistance & 16.58 & 11.09 & 1.21 & 3.08 \\
Retired Residents & 61.59 & 21.77 & 1.13 & 2.45 \\
Non-White Residents & 90.95 & 246.01 & 7.87 & 68.98 \\
\hline
\end{tabular}


Re-entry rates and greater concentrations of incarceration contribute to crime; the results demonstrate statistically significant strong positive linear relationship between reentry rates and juvenile crimes $(\mathrm{r}=0.558, p<0.01)$ A statistically significant negative linear relationship between re-entry rates and proportions of non-profit employees $(r=-$ $0.269, p<0.05)$ was also found. A statistically significant strong negative linear relationship was found between the rate of re-entry and proportion of self-employed residents $(\mathrm{r}=-0.476, p<0.01)$. Results also point to a statistically significant strong positive linear relationship between re-entry rates and neighborhood church rates $(\mathrm{r}=$ $0.408, p<0.01)$.

Rates of re-entry had a negative relationship with the proportions of neighborhood residents with house-hold income above $50 \mathrm{~K}$, which neared the statistically significant level $(r=-0.040)$. A statistically significant strong positive linear relationship between reentry rates and the proportion of neighborhood residents receiving government assistance $(\mathrm{r}=0.619, p<0.01)$ was found; a statistically significant negative linear relationship exists between re-entry rates and proportions of retired residents $(r=-0.240, p<0.05)$. A statistically significant strong positive linear relationship between re-entry rates and the proportion of residents which graduated from high school was found $(\mathrm{r}=0.587, p<$ 0.01). A statistically significant positive linear relationship was found between re-entry rates and the proportion of non-white neighborhood residents $(\mathrm{r}=0.229, p<0.05)$.

Human and social capital indicators have an impact on juvenile crime rates; a negative relationship between juvenile crime and the proportion of neighborhood residents employed by non-profits was found, which approaches statistical significance (r 
$=-0.056)$. A statistically significant strong negative linear relationship between the rate of juvenile crime and the proportions of self-employed neighborhood residents $(\mathrm{r}=-0.556, p$ $<0.01)$ was found.

Table 2

Bivariate Correlations Using Pearson's $r$

\begin{tabular}{lcc}
\hline & Juvenile Crime & Re-entry \\
\hline Juvenile Crime & 1 & $0.558^{* *}$ \\
Re-entry & $0.558^{* *}$ & 1 \\
Non Profit Employees & -0.56 & $-0.269^{*}$ \\
Self-Employed Residents & $-0.556^{* *}$ & $-0.476^{* *}$ \\
Churches & $0.223^{*}$ & $0.408^{* *}$ \\
House-hold Income, 50K+ & $0.613^{* *}$ & -0.040 \\
Government Assistance & $0.440^{* *}$ & $0.619^{* *}$ \\
Retired Residents & -0.182 & $-0.240^{*}$ \\
High School Graduates & $0.443^{* *}$ & $0.587^{* *}$ \\
Non-White Residents & $-0.261^{*}$ & $0.229^{*}$ \\
\hline
\end{tabular}

*. Correlation is significant at the 0.05 level (2-tailed)

**. Correlation is significant at the 0.01 level (2-tailed)

A statistically significant positive linear relationship was found between juvenile crime rates and the rate of neighborhood churches $(\mathrm{r}=0.223, p<0.05)$. A statistically significant strong positive linear relationship between juvenile crime rates and the proportions of residents with house-hold incomes above $50 \mathrm{~K}(\mathrm{r}=0.613, p<0.01)$ was also found. A statistically significant strong positive linear relationship between juvenile crime rates and the proportion of neighborhood residents receiving government assistance $(\mathrm{r}=0.440, p<0.01)$ was found. A negative linear relationship between juvenile crime rates and the proportion of retired residents was found $(r=-0.182)$, which approached 
statistical significance. A statistically significant strong positive linear relationship between juvenile crime rates and the proportion of neighborhood residents with a high school diploma was found $(r=0.443, p<0.01)$. A statistically significant negative linear relationship was found between juvenile crime rates and the proportion of non-white neighborhood residents $(\mathrm{r}=-0.261, p<0.05)$.

Ordinary least squares (OLS) regression analysis was employed to evaluate how well human capital variables (house hold income above 50K and type of income, retired or government assistance, and high school graduation per capita for 2000) and social capital variables (neighborhood rate of non-profit, self-employment, and churches per capita for 2000) mitigate the effects of reentry rates (neighborhood rate of re-entry per capita for 1997-2002) on juvenile crime (neighborhood rate of juvenile arrests per capita for 2006-2008), controlling for race (proportion of non-white residents per capita 2010). Results for the model are shown in Table 3.

Approximately $77 \%$ of the variance in juvenile crime rates was explained by house-hold income above 50K and type of income, retired or government assistance, proportion of neighborhood residents with a high school diploma, neighborhood rate of non-profit, self-employment, churches and re-entry rates, $\mathrm{R}^{2}=0.766, F=28.681, p<$ 0.05. The relationship of the rate of re-entry to the neighborhood rate of juvenile crimes was statistically significant, $\mathrm{t}=2.735, p=<0.05$. Specifically, for every one unit increase in the amount of logged re-entry rates, there is an expected increase of 0.008 in the logged number of juvenile crimes at the neighborhood level. The relationship of the rate residents with house-hold income above $50 \mathrm{~K}$ to the neighborhood rate of juvenile crimes 
was statistically significant, $\mathrm{t}=10.180, p=<0.05$. Specifically, for every one unit increase in the rate of neighborhood residents with house-hold income above $50 \mathrm{~K}$, there is an expected increase of 0.0003 in the logged number of juvenile crimes at the neighborhood level. The relationship of the rate of neighborhood residents receiving government assistance to the neighborhood rate of juvenile crimes was statistically significant, $\mathrm{t}=3.388, p=<0.05$. Specifically, for every one unit increase in the rate of neighborhood residents receiving government assistance, there is an expected increase of 0.001 in the logged number of juvenile crimes at the neighborhood level. The relationship of the rate of retired neighborhood residents to the neighborhood rate of juvenile crimes was statistically significant, $\mathrm{t}=-2.549, p=<0.05$. Specifically, for every one unit increase in the rate of retired neighborhood residents, there is an expected decrease of 0.013 in the logged number of juvenile crimes at the neighborhood level. The relationship of the rate of neighborhood residents receiving government assistance to the neighborhood rate of juvenile crimes was statistically significant, $\mathrm{t}=3.388, p=<0.05$. Specifically, for every one unit increase in the rate of neighborhood residents receiving government assistance, there is an expected increase of 0.001 in the logged number of juvenile crimes at the neighborhood level.

Table 4 details the bivariate regression of slopes for all variables and juvenile crime and re-entry. Major points of interest include: the relationship between juvenile crime and government assistance, $\mathrm{B}=7.318$, and retired residents, $\mathrm{B}=-10.926$ and the relationship between re-entry and house-hold income above $50 \mathrm{~K}, \mathrm{~B}=-7.51$. These large slope values reflect a greater interaction between the independent variable (re-entry), 
human capital variables (retired residents, residents receiving government assistance and house-hold income above 50K) and the dependant variable (juvenile crime).

Table 3

Model 1, OLS Regression for Juvenile Crime

\begin{tabular}{lccc}
\hline & B & Juvenile Crime & Beta \\
\hline Re-entry & 0.307 & 0.281 & Significance \\
Non Profit Employees & 0.002 & 0.039 & $0.008^{*}$ \\
Self-Employed & -0.009 & -0.124 & 0.632 \\
Residents & & & 0.112 \\
Churches & -0.006 & -0.004 & 0.952 \\
House-hold Income, & 0.001 & 0.588 & $0.000^{*}$ \\
50K+ & & & \\
Government Assistance & 8.149 & 0.308 & $0.001^{*}$ \\
Retired Residents & -13.472 & -0.229 & $0.013^{*}$ \\
High School Graduates & 4.138 & 0.002 & 0.986 \\
Non-White Residents & 0.001 & 0.156 & 0.074 \\
\hline
\end{tabular}

$*$ Significant at $\mathrm{p}<0.05$

Table 4

Bivariate Regression of Slopes for Juvenile Crime and Re-entry

\begin{tabular}{lcl}
\hline & Juvenile Crime & Re-entry Slope \\
\hline Juvenile Crime & NA & 0.510 \\
Re-entry & 0.610 & NA \\
Non Profit Employees & -0.004 & -0.015 \\
High School Graduates & 0.010 & 0.012 \\
Self-Employed Residents & -0.042 & -0.033 \\
Churches & 0.335 & 0.535 \\
House-hold Income, 50K+ & 0.001 & -7.510 \\
Government Assistance & 7.318 & 0.063 \\
Retired Residents & -10.926 & -0.012 \\
Non-White Residents & 3.446 & 0.006 \\
\hline
\end{tabular}




\section{Discussion}

The aim of this study was to understand the role of human and social capital measures of neighborhoods (2000) as mitigating influences on the relationship between re-entry rates (1997-2002) and juvenile crime rates (2006-2008), controlling for race (2010). We anticipated a mediating relationship of human and social capital measures between re-entry rates and juvenile crime rates of neighborhoods in Portland, Oregon. To analyze a mediating affect, a direct relationship between the independent variable (reentry rates) and the dependant variable (juvenile crime rates) must be established.

A strong direct effect between re-entry rates and juvenile crime rates was found. Bivariate correlations found an affect between re-entry and juvenile crime rates, which is consistent with the literature (Macleod, 1987; Western, et al., 2000; Clear, 2001). Reentry has been linked with the augmentation of the supply of disadvantaged workers, confined to secondary labor markets (Macleod, 1987; Western, et al., 2000; Clear, 2001). Increases in the numbers of disadvantaged workers may produce a tipping point, where the supply of employment has a limiting effect on the demand of potential employees, resulting in fewer employment opportunities in the licit labor market. Few gain access to legitimate employment, but all residents need some economic capital to sustain life. In order to meet economic demands, some residents, who are excluded from the licit labor market, will turn to the illicit labor market to secure economic capital (Macleod, 1987; Western, et al., 2000; Clear, 2001). However, economic literature concerning the utilization of human and social capital skills is limited: few studies examine the relationship between juvenile economic investment, crime and re-entry. As, such, future 
study is needed to flesh out the nuances between the influence of re-entry or juvenile crime and the relationship to minors in the work force.

The next step in establishing a mediating relationship involves demonstrating a relationship between the initial variable (re-entry) and the mediator (high-school graduation, house hold income above $50 \mathrm{~K}$ and type of income: retired or government assistance, neighborhood rate of non-profit, self-employment, and the rate of churches); this relationship was explored using bivariate correlations. Again, an affect was found. Moderately strong negative relationships between the rate of self-employed residents and re-entry rates were found. Self-employed persons are thought to exhibit high levels of both human and social capital, reflected in their ability to transform an idea for employment into an economically viable entity. As persons with interests in selfemployment advance their goal, they come into contact with other networks of people who have answers to their questions. These networks of self-employment acquaintances link those with self-employment aspirations to others that have answers to their questions. In short, those interested in becoming self-employed have more bridging networks of obligations than do people who are uninterested in self-employment.

Human capital levels of residents who are self-employed are visible when one examines the extent of their cross-training: self-employed residents have acquired bookkeeping, accounting, scheduling, and other managerial functions in addition to skills associated with running a business on the floor. Increases in both human and social capital levels are negatively correlated with increased adult crime (Western et al, 2000; Putnam, 2001; Coleman, 1988), but also are negatively correlated with re-entry rates. Re- 
entry rates, in this instance, represent aggregated levels of human and social capital of the formerly incarcerated. The very nature of removal from licit market functions, coupled with increased criminal human and social capital acquired while incarcerated, make entering into traditional or more ambitious forms of labor, like self-employment, increasingly difficult (Western et al., 2000; Clear, 2001).

Many theorists have commented on the relationship between increased household income and reduced crime and re-entry rates (Becker, 1964, 1967; Ben-Porath, 1967; Kennedy et al, 1998; Lochner, 1999; Grossman, 2000; Lochner, 2004). Increases in house-hold income are products of time investments made in acquiring increased human capital levels. Using the Ben-Porath model, individuals who have higher income levels have incentives to increase their human capital; increased economic capital is a product of increased human capital and represents participation in the licit labor market. According to Lochner $(1999,2004)$, increases in human and economic capital lead to decreased time available to participate in illicit market functions, or crime. Formerly incarcerated persons must have participated in illicit market functions, inherent in their incarceration status, and therefore either had limited success in licit market activities, which influence decisions to resign from legal employment all together, or supplemented their licit income with illicit funds. In addition, Lochner (2004) points to the relationship between decreased education levels and skill sets amongst juveniles who participate in low skilled crimes. Deficiencies in education and skills suggest decreased human capital levels, which reflect upon income levels, as products of human capital. Our study found a negative relationship between re-entry rates and the rate of neighborhood residents with 
house-hold income above 50K, which neared statistical significance. Literary scholars document the relationship between increased income and decreased crime. These findings support an extension of the hypothesis high income levels lead to decreased crime rates: if income is inversely related to crime rates, income should be inversely related to incarceration rates and re-entry rates because decreases in crime lead to decreased arrest, prosecution, incarceration and subsequent re-entry rates.

Portland neighborhood rate of churches and increased social services have been linked to neighborhoods with the highest returnee rates; social services tend to be corroborated with increased need of neighborhood residents (Renauer et al., 2006). However, formerly incarcerated persons' placement into Portland neighborhoods is not wholly dependent on the rate of churches or other social services available (Covelli, 2008); placement seems to be made on an individual case basis. The current model found a statistically significant positive relationship between re-entry rates and the neighborhood rate of churches. This finding indicates the rate of neighborhood churches cannot fully mitigate against increases in re-entry rates, or other influences. However, the literature suggests that religious involvement has a buffer effect, which can insulate against negative impacts of neighborhood disorder (Covelli, 2008). In the current analysis, the neighborhood rate of churches is positively related to neighborhood re-entry rates. Perhaps, because the neighborhood rate of churches and the formerly incarcerated persons who choose to reside within those neighborhoods is not determined by the formerly incarcerated, the insulation effect cannot be clearly shown. Although churches have been shown to provide a positive impact on the lives of participants, perhaps the 
levels of human and social capital participants gain by going to church is not enough to mitigate the effects of social disorganization at the neighborhood level.

The current study shows re-entry rates have a positive effect on the rates of residents receiving government assistance, which is a proxy for poverty levels. Higher rates of formerly incarcerated individuals have been shown to reside in neighborhoods with higher levels of low-income housing, even when controlling for concentrated disadvantage measures (Covelli, 2008). When considering the relationship between reentry rates and measures of concentrated disadvantage, eight of ten Portland neighborhoods with the highest levels of formerly incarcerated persons ranked in the top ten neighborhoods with concentrated disadvantage indicators (Covelli, 2008). Concentrated disadvantage neighborhoods are characterized by subcultures that condone crime and violence, confusion surrounding community norms, decreases in social ties and networks, less informal social control and increased fear, which can result in withdrawal from the community (Covelli, 2008). Human and social capital theories suggest that incarceration deteriorates human and social capital levels of the formerly incarcerated (Western et al., 2000; Clear, 2001). As returnees attempt to gain some resemblance of normalcy in their day-to-day lives and fulfill the requirements of post incarceration supervision, they must gain legal employment. However, depleted human and social capital makes finding legal employment difficult; deficits in education, job skills and decreased legal employment opportunities, made known through social networks, contribute to such difficulties. In addition, extraction from the home due to incarceration 
leaves deficits in the amount of income available to the remaining family members, resulting in increased use of public assistance (Macleod, 1987; Clear, 2001).

A negative relationship between re-entry rates and the proportions of retired Portland neighborhood residents was found. This phenomenon is explained by social capital literature; persons who have retired have more obligatory networks of individuals to share information with than do individuals who have not retired, due to increases in time allotted for socializing instead of working. As social capital levels of retirees rise, trust among neighborhood residents increases (Coleman, 1988). Residents with increased levels of trust tend to socialize more with their neighbors or others in their communities (Putnam, 2001); the logic of game theory continues to apply (Putnam, 2001) resulting in decreases in formal contract formation or formal complaints to the police, which decreases crime and re-entry rates.

Neighborhood residents with a high school diploma tend to positively influence re-entry rates. At first glance, this finding seems to be inconsistent with the literature, but on closer inspection, this finding has consistencies after all. Oregon Department of Corrections has adhered to providing services for incarcerated individuals that are rooted in evidence based practices, which have been empirically proven to increase desistance rates amongst returnees (Van Voorhis, 2007). Evidence based practices focus on building skill sets necessary to help navigate the world outside prison more effectively by aligning treatment programs to the prisoner's risk, needs and responsivity levels determined by the LSIR evaluation form, administered when the prisoner arrives at the institution; programs designed to enhance anger management techniques, job skills, high school diploma 
attainment and many others tend to increase the human and social capital levels of those incarcerated. Although, overall net deficits in human and social capital levels of the incarcerated have been found (Western et al, 2000; Clear, 2001), Oregon inmates have opportunities to lessen the degree to which net deficiencies in human and social capital surmount. It is important to note that individuals who have been incarcerated have decreased human and social capital levels, at both the individual and group level, as compared to non-incarcerated individuals. Oregon inmates, and other inmates provided with evidence based practice prison programs, however, tend to have higher human and social capital levels, at both the individual and group level, than inmates that have not been provided such services. Nevertheless, increased human capital among returnees is not enough to outweigh the much larger density of imprisonment indicated here.

Rates of neighborhood residents employed by non-profit organizations are negatively associated with re-entry rates. The negative relationship between rates of nonprofit employees and re-entry rates found for Portland neighborhoods is consistent with the literature (Western et al, 2001; Putnam, 2001; Coleman, 1988). Employment is hypothesized to be a product of an increased level of skill, education or networking ability, which allows access to opportunity (Western et al, 2001; Putnam, 2001; Coleman, 1988). Current findings point to increases in neighborhood levels of human and social capital reflected in decreased re-entry rates. Non-profit employees not only cue other neighborhood residents towards employment opportunities, but also may inspire residents to volunteer at non-profits in the neighborhood. Social capital theory suggests both employment and volunteer opportunities represent increases in obligations between 
individuals, in the first example, or groups of individuals, referred to in the second. Either instance of increasing obligations induce residents to reciprocate such opportunities, either by gaining employment and providing others with employment opportunities or giving back to the community by volunteering.

The third step in establishing a mediating relationship is showing that the mediators (high school graduation, house hold income above $50 \mathrm{~K}$ and type of income, retired or government assistance, neighborhood rate of non-profit, self-employment, and the rate of churches) affects the outcome variable (juvenile crime rates); this relationship was explored using bivariate correlations. Again, these relationships were significant for the rate of churches, the rate of house-hold income above 50K, residents with high school degrees and residents receiving government assistance.

Neighborhood rates of self-employed residents have a negative effect on rates of juvenile arrest. Self-employed residents not only have higher levels of human and social capital, as noted above, they also have an increased opportunity to work from home, as compared to traditional employment. Persons who work from home have an increased ability to deter juvenile crime by their very presence in the residence. Youth who may attempt to commit property crimes will desist from illegally entering or defacing property of residents who are present and can easily call the police, detain or identify perpetrators; other forms of crime theoretically would be just as easy to deter. Also, residents who work at home provide protection to other neighborhood residents because of their presence in the neighborhood during times otherwise used for working. Neighborhood- 
watch organizations typify this type of surveillance, however, members may or may not be self-employed.

Neighborhood rate of churches has a positive effect on the amount of juvenile delinquency. In much the same way rate of churches influences the rate of re-entry, churches tend to increase juvenile arrests. Measures of disadvantage in some Portland neighborhoods tend to override the beneficial effects of religious participation. Namely, decreased levels of informal social control, one measure of disadvantage, appears to have an effect on the number of juvenile arrests. This finding is contrary to social capital literature; religious participation is theorized to increase obligatory networks and reduce adverse behaviors. In addition, church membership represents closely bonded groups of individuals, which exert more informal social control surrounding group norms than loosely bonded individuals (Putnam, 2001).

Interestingly, rates of neighborhood residents with a high school diploma positively influence juvenile crime rates. Increased education and skill sets have been correlated with decreases in juvenile crimes (Western et al.,2000). Increases in education also help individuals gain licit employment (Bourdeau, 1983). Perhaps a high school education does not capture the increased skill necessary to negatively affect juvenile crime rates. Unfortunately, our current model cannot fully explain this relationship.

Rates of juvenile delinquency are positively influenced by the proportion of neighborhood residents with house-hold income above 50K. Results indicating increases in juvenile arrest rates coincide with increased house-hold income has not received as 
much notoriety; in fact, these results are contrary to what the literature would predict (Becker, 1964, 1967; Ben-Porath, 1967; Kennedy et al, 1998; Lochner, 1999; Grossman, 2000; Lochner, 2004). One speculation as to why such results are found in Portland points to zoning laws and increases in mixed-use land management strategies intended to limit sprawl and increase urban density. The institution of an urban growth boundary in the 1970s dramatically altered the ability of Portland to expand in more traditional ways, as seen in cities across the nation-Las Vegas being a prime example of expansion and sprawl (Bruegman, 2005). As Portland expanded to the limits of the urban growth boundary, vertical accommodations and mixed use zoning mitigated the effects of increases in residency, resulting in neighborhoods which house residents with larger house-hold income in conjunction with the homeless, returnees, substance abuse and mental health facilities and youth shelters-the Pearl is a prime example of this "unusual" neighborhood.

The final step in establishing a mediating affect is to establish that the mediators (human and social capital variables) completely or partially mediate the relationship between the independent (re-entry rates) and dependant variables (juvenile crime rates). The bivariate relationship between re-entry rates and juvenile crime rates has been established: re-entry rates are positively associated with increases in juvenile arrest rates. When comparing the relationship between re-entry rates, juvenile crime rates and human and social capital indicators at the neighborhood level, a statistically significant effect is evident: rates of self-employment, the rate of churches, the rate of residents with household incomes above $50 \mathrm{~K}$, and the rate of residents receiving government assistance, rates 
of retired residents, residents with high school diplomas and residents employed by nonprofit organizations were correlated with re-entry rates; rates of non-profit employees, rates of retired residents, rate of churches, rate of house-hold income above $50 \mathrm{~K}$, rates of residents with high school diplomas, and residents receiving government assistance were correlated with juvenile crime rates.

The OLS regression model compares the relationship between re-entry rates and human and social capital indicators to rates of juvenile crime, while controlling for race. Results indicate a mediation effect between re-entry rates and juvenile crime rates. In other words, aggregate levels of human and social capital indicators tend to create a buffer among the relationship between re-entry and juvenile crime. For neighborhoods with higher concentrations of re-entry, the human and social capital levels of other neighborhood residents mitigate against the effect of juvenile crime. Although neighborhoods with high levels of incarceration have higher rates of juvenile crime, our study finds rates of juvenile crime are affected by the human and social capital of the other neighborhood residents. Neighborhoods with higher proportions of residents who are self-employed or work for non-profits, who are retired, who graduated from high school and who do not receive government assistance have fewer rates of returnees and fewer juvenile arrests.

Human capital variables that had the most mediating influence are: house-hold income above $50 \mathrm{~K}$, proportion of retired neighborhood residents and proportions of residents receiving government assistance. Both income and government assistance rates have a positive mediating effect on juvenile arrest rates; increases in the amount of 
house-hold income and increased proportions of residents receiving government assistance lead to increases in juvenile offending. Conversely, rates of retired neighborhood residents tend to decrease juvenile crime in Portland neighborhoods. The OLS regression model predicts approximately $77 \%$ of the variance of juvenile offending rates when comparing re-entry rates and human and social capital indicators. This finding is important because it reflects the impact of human and social capital indicators on the relationship between re-entry rates and the rates of juvenile crime for Portland neighborhoods. The study provides evidence of the necessity of including measures of human and social capital levels when assessing the relationship between re-entry and crime.

\section{Limitations}

Although this study suffers from numerous limitations, it provides fairly accurate descriptions of human and social capital of Portland neighborhoods, and their mitigating effects on the relationship between re-entry rates and juvenile crime rates. Procedures were taken to gather complete data measures; however, it is important to note that in the returning offender data there were several unmappable or missing addresses which may underestimate the re-entry rates of some neighborhoods in Portland, Oregon. There is no reason to believe that the missing data are biased towards any particular neighborhood in Portland, so overall conclusions are likely to be unaffected.

One danger of using human and social capital measures to assess neighborhood disorganization levels is such conceptions can be construed as a deficit theory, or the idea 
that some neighborhoods lack something, whether at the individual or community level. Human and social capital indicators merely suggest plausible explanations about why some neighborhoods experience differences in re-entry and crime rates; human and social capital theories do not provide causal determinants between human and social capital indicators and crime, arrest and incarceration effects. A more heuristic approach to determine neighborhood success or failures under the guise of human and social capital theories may reflect more accurate data collection and analysis methods.

\section{Conclusion}

Understanding the characteristics of neighborhoods with formerly incarcerated persons and their influence on later crime is important for future research and for promoting more informed decision making about incarceration policy and the development of healthy communities. Most notably, understanding the many caveats to the creation and maintenance of human and social capital at the individual and neighborhood level will shed light on the many difficulties communities face with regards to re-entry and crime control. Rates of re-entry were shown to have direct effects on levels of juvenile delinquency for neighborhoods in Portland, Oregon. Furthermore, levels of human and social capital have shown mediation affects on the rates for juvenile crimes; retired residents, residents employed by non-profit organizations, residents who have received high school diplomas and self-employed residents tend to reside in neighborhoods with decreased juvenile crime rates. Rates of re-entry are positively 
associated with the neighborhood rate of churches, house-holds with income levels above 50K, residents with high school diplomas and residents receiving government assistance. Future research and replication is needed to determine the mediating effect of human and social capital indicators on the relationship between re-entry rates and juvenile crime rates over time. 


\section{References}

Akom, A. (2008). Ameritocracy and infra-racial racism: Racializing social and cultural reproduction theory in the twenty-first century. Race Ethnicity and Education, 11(3), p. 205-230.

Arrow, K. (1998). What has economics to say about racial discrimination? The Journal of Economic Perspectives, 12 (2), p.91-100.

Becker, G. (1968). Crime and punishment: An economic approach. The Journal of Political Economy. 76(2), p. 169-217.

Benabou, R. (1996). Equity and efficacy in human capital investment: The local connection. The Review of Economic Studies. 63(2), p. 237-264.

Bourdieu, P. (2001). The forms of capital. Sociology of Economic Life.

Bourdieu, P. (1989). Social space and symbolic power. Sociological Theory. 7(1), p. 1425.

Bonczar, T. \& Beck, A. (1997). Lifetime likelihood of going to state or federal prison. Bureau of Justice Statistics Special Report. NCJ 160092.

Braman, D. (2004). Doing time on the outside: incarceration and family life in urban america. Ann Arbor: University of Michigan Press.

Briggs, X. (1997). Social capital and the cities: Advice to change agents. The National Civic Review.

Bruegman, R. (2005). Sprawl. Chicago and London: The University of Chicago Press. 
Carroll, M. \& Stanfield, J. (2003). Social capital, Karl Poianyi and American social institutional economics. Journal of Economic Issues. 37(2), p. 397-404.

Covelli E. (2008). Characteristics of neighborhoods with returning offenders: Social services, churches, low-cost housing and concentrated disadvantage. Unpublished master's thesis, Portland State University.

Coleman J. (1988). Social capital in the creation of human capital. The American Journal of Sociology. 94, p. 95-120.

Ehrlich, I. (1973). Participation in illegitimate activities: A theoretical and empirical investigation. The Journal of Political Economy. 81(3), p. 521-565.

Fearon, J. (2003). Ethnic structure and cultural diversity around the world: A crossnational data set on ethnic groups. 2002 Annual Meeting of the American Political Science Association, Aug. 29-Sept. 1, Boston, Stanford University.

Forrest, R. \& Kearns, A. (2001). Social cohesion, social capital and the neighborhood. Urban Studies. 38(12), p. 2125-2143.

Grossman, M. (2000). The human capital model. Handbook of Health Economics, 7, p. 348-405. 
Hagan, J. \& Dinovitzer, R. (1999). Collateral consequences of imprisonment for children, communities, and prisoners. Crime and Justice: A Review of Research, 26, p. 121-62.

Hagan, J. \& Palloni, A. (1990). The social reproduction of a criminal class in workingclass London, circa 1950-1980. The American Journal of Sociology, 96(2), p. 265-299.

Information Network for Health 2001. [Unpublished handbook for data listing]. Salem, OR: Oregon Department of Corrections.

Ioannidies, Y. \& Loury, L. (2004). Job information networks, neighborhood effects and inequality. Journal of Economic Literature. XLII, p. 1056-1093.

Kawachi, I., Kennedy, B. \& Wilkinson, R. (1999). Crime: Social disorganization and relative deprivation. Social Science Medicine. 48, p. 719-731.

Kennedy, B., Kawachi, I., Prothrow-Stith, D., Lochner, K. \& Gupta, V. (1998). Social capital, income inequality and firearm violent crime. Social Science Medicine. 47(1), p. 7-17.

Lederman, D., Loayza, N. \& Menendez, A. (2002). Violent crime: Does social capital matter? Economic Development and Cultural Change. 50(3), p. 509-539.

Lochner, L. (1999). Education, work and crime: Theory and evidence. Rochester Center for Economic Research. Working Paper No. 465.

Lochner, L. (2004). Education, work, and crime: A human capital approach. NBER Working Paper Series. 10478. 
Lochner, K., Kawachi, I. \& Kennedy, B. (1999). Social capital: A guide to its measurement. Health \& Place. 5, p. 259-270.

Lochner, K., Kawachi, I., Brennan, R. \& Buka, S. (2003). Social capital and neighborhood mortality rates in Chiago. Social Science Medicine. 56, p. 17971805.

Macleod, J. (1987/1995). Chapters 1 and 2. In Ain't no makin' it: Aspirations and attainment in a low income neighborhood. Boulder, CO: Westview Press.

Mc Carthy, B. \& Hagan, J. (2001). When crime pays: Capital, competence and criminal success. Social Forces. 79(3), p.1035-1060.

Mission Portland (2007). Mission Portland: Churches by region, 2007 [Data file]. Available from Mission Portland website at www.missionportland.org.

Mocan, N., Billups, S. \& Overland, J. (2000). A dynamic model of differential human capital and criminal activity. National Bureau of Economic Research. Working Paper 7584.

Multnomah County parole and Probation (2007). Listing of parole and probation offices and recommended treatment centers [Unpublished listing for data file]. Portland, OR: Parole and Probation Services.

Need Help (2007). Need help directory: Find a church [Data file]. Available from Need Help Directory website at www.needhelpdirectory.com. 
Oregon Department of Corrections (2007). Oregon department of corrections:

Community population profile. Retreived on May 3, 2007, from http://www.oregon.gov/DOC/RESEARCH/

Outside In (2007). Listing of social services for Portland, Oregon [Data file]. Portland, OR: Outside In.

Pager, D. (2003). The mark of a criminal record. American Journal of Sociology. 108, p. $937-75$.

Portes, A. (1998). Social capital: Its origins and applications in modern sociology. Annu. Rev. Sociol. 24, p. 1-24.

Putnam R. (2001). Social capital: Measurement and consequences. Canadian Journal of Policy Research. p. 1-32.

Putnam R. (2000). Bowling alone: the collapse and revival of American community. Simon \& Schuster Paperbacks.

Renauer, B., Cunningham, W., Feyerherm, B., O’Connor, T. \& Bellatty, P. (2006). Tipping the scales of justice: The effect of over incarceration on neighborhood violence. Criminal Justice Policy Review, 17(3), p. 362-379.

Rose, M. (1989). Lives on the boundary: A moving account of the struggles and achievements of America's educationally underprepared. New York: Penguin Group.

Schmid, T. \& Jones, R. (2009). Ambivalent actions: Prison adaptation strategies of firsttime, short-term inmates. Prisons and Jails. McGraw Hill Higher Education. 
Schnittker, J. \& John, A. (2007). Enduring Stigma: The Long-Term Effects of Incarceration on Health.Journal of Health and Social Behavior. 48, p.115.

West, H. \& Sabol, W. (2010). BJS Statisticians. Greenman, S., (2010), BJS Program Assistant.NCJ 231675 BJS http://bjs.ojp.usdoj.gov/content/pub/pdf/p09.pdf.

Western, B., Kling, J. \& Weiman, D. (2000). The labor market consequences of incarceration. Princeton University. Working Paper \# 450.

Woolcock, M. \& Narayan, D. (2000). Social capital: Implications for development theory, research and policy. The World Bank Observer. 15(2), p. 225-249.

Zimring, F. (2009). Imprisonment rates and the new politics of criminal punishment. Prisons and Jails. Mc Graw Hill Higher Education. 